\title{
Built-up edge effects on process outputs of titanium alloy micro milling
}

\author{
Samad Nadimi Bavil Oliaei ${ }^{a}$, Yigit Karpat ${ }^{\mathrm{a}, \mathrm{b}, \mathrm{c}, *}$ \\ a Bilkent University, Department of Mechanical Engineering, Micro System Design and Manufacturing Center, Bilkent, Ankara, Turkey \\ b Bilkent University, Department of Industrial Engineering, Bilkent, Ankara, Turkey \\ ' UNAM - Institute of Materials Science and Nanotechnology, Turkey
}

\section{A R T I C L E I N F O}

\section{Article history:}

Received 28 October 2016

Received in revised form 23 January 2017

Accepted 22 February 2017

Available online 6 March 2017

\section{Keywords:}

Micro milling

Micro tools

Built-up edge

Titanium alloy

\begin{abstract}
A B S T R A C T
Built-up edge (BUE) is generally known to cause surface finish problems in the micro milling process. The loose particles from the BUE may be deposited on the machined surface, causing surface roughness to increase. On the other hand, a stable BUE formation may protect the tool from rapid tool wear, which hinders the productivity of the micro milling process. Despite its common presence in practice, the influence of BUE on the process outputs of micro milling has not been studied in detail. This paper investigates the relationship between BUE formation and process outputs in micro milling of titanium alloy Ti6Al4V using an experimental approach. Micro end mills used in this study are fabricated to have a single straight edge using wire electrical discharge machining. An initial experimental effort was conducted to study the relationship between micro cutting tool geometry, surface roughness, and micro milling process forces and hence conditions to form stable BUE on the tool tip have been identified. The influence of micro milling process conditions on BUE size, and their combined effect on forces, surface roughness, and burr formation is investigated. Long-term micro milling experiment was performed to observe the protective effect of BUE on tool life. The results show that tailored micro cutting tools having stable BUE can be designed to machine titanium alloys with long tool life with acceptable surface quality.
\end{abstract}

(c) 2017 Elsevier Inc. All rights reserved.

\section{Introduction}

Micro milling offers high flexibility in terms of its ability to create three-dimensional surfaces made from a variety of engineering materials. For example, micro milling is a commonly used process to produce micro molds, which are used in mass production of micro components $[1,2]$. The material removal in micro milling is realized by using micro end mills, which have defined cutting geometries. The micro end mills have diameters less than $1 \mathrm{~mm}$. The influence of micro end mill diameter on the process outputs becomes significant as the tool diameter decreases. The cutting edge geometry and surface quality of the micro tool, together with the work material properties, have a direct influence on the quality of the manufactured parts [3]. Small diameters of micro end mills limit the maximum cutting speed during the process. In addition, feed values lower than the cutting edge radius results in rapid rounding of the cutting tool edge. When ductile materials such as

\footnotetext{
* Corresponding author at: Bilkent University, Department of Industrial Engineering, Bilkent, Ankara, Turkey.

E-mail address: ykarpat@bilkent.edu.tr (Y. Karpat).
}

steel, aluminum, and titanium alloys are machined, built-up edge (BUE) is observed on the cutting edges and it affects the process outputs and especially the surface roughness. An understanding of the interplay between tool wear, built-up edge, and surface quality for a given tool-work material pair is crucial for the successful application of the micro milling process. The work material is selected as titanium alloy Ti6Al4V due to its widespread use in practice [4-6].

The influence of BUE on machining has been considered mainly for macro scale machining processes [7-9]. However, the influence of BUE on the micro milling process has not been studied in detail. Thepsonti and Özel [10] observed BUE formation in micro milling of titanium alloy Ti6AL4V. Recently, Kovvuri et al. [11] and Wang et al. [12] studied the influence of BUE while machining 316L stainless steel and reported that BUE is mainly responsible for surface roughness deterioration in the finish micro milling process. They showed that when BUE is not present, theoretical surface roughness models yield acceptable predictions. Ucun et al. [13] and Aslantas et al. [14] both studied the finish micro milling operation and observed that coated tools minimize BUE and help improve surface roughness.

BUE affects the friction conditions at the tool-chip and toolworkpiece interfaces by acting like a cutting edge so that the cutting tool material is no longer in contact with the chip and the machined 


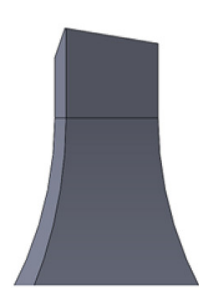

Front View
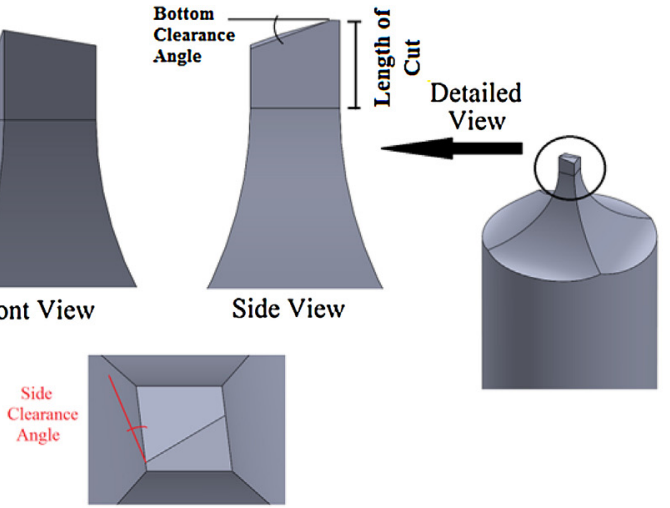

Top View

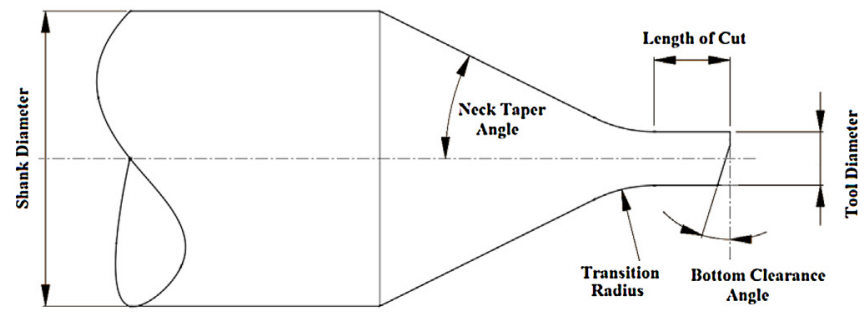

(b)

(a)

Fig. 1. (a) Geometry of the designed single edge cutting tool, (b) Design parameters of the tool.

surface. Iwata and Ueda [15] studied machining of low carbon steel and observed that fracture behavior of the work material affects BUE formation and its adhesion to the tool. They reported that tool rake temperature between 350 and $500^{\circ} \mathrm{C}$ provided the necessary conditions for BUE to adhere to the cutting tool surface. The influence of rake face temperature on the adherent layer was also observed by Mills et al. [16] while machining calcium dioxide low sulphur content austenitic stainless steel. Kümmel et al. [17,18] created dimples on the tool surface to promote BUE formation during macro scale turning operation. The dimples on the cutting tool surface increase BUE adhesion on the cutting tool, hence improving the tool life. Oliaei and Karpat [19] fabricated micro cutting tools using wire electrical discharge machining, which creates micro scale craters on the surface of the tool, which was also shown to promote BUE adhesion during machining. The protective effect of BUE was shown for micro turning process. In this study, this approach is carried out during micro milling of titanium alloy Ti6Al4V by fabricating micro cutting tools using wire electrical discharge machining (WEDM). The influence of BUE on the process outputs is investigated. The research question is whether tool design parameters and machining conditions can be adjusted to obtain a stable BUE that protects the cutting edge. This may be especially useful to increase material removal rate during micro milling operation.

Various techniques have been used to fabricate micro end mills in the literature [20,21]. End mills fabricated via electrical discharge machining (EDM) have been shown to work effectively on metal alloys and polycrystalline diamond [22-24]. The surface integrity and cutting edge radius are two important issues. Studies have shown that tailored micro end mills designed for specific machining cases yield comparable performance compared to conventional micro end mills [25]. Compared to conventional micro end mills, which are produced through grinding process to have helical flute geometry, these tools usually have straight edges, which improves the stiffness but limits the chip evacuation. The use of straight edges can be justified by considering the low depth of cut values in micro milling.

In this study, a single cutting edge micro end mill has been fabricated using wire electrical discharge machining. The influence of micro end mill surface quality and design parameters on the micro milling process has been investigated. A tool design for stable BUE formation was selected. The effect of BUE on the micro milling process outputs such as surface roughness and burr formation was investigated for the set geometry.

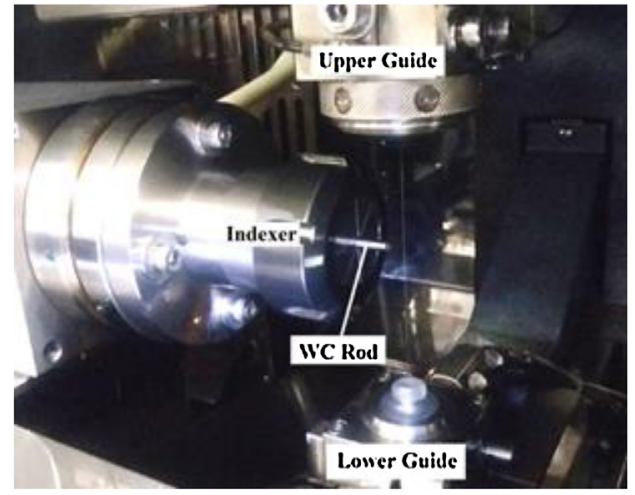

(a)

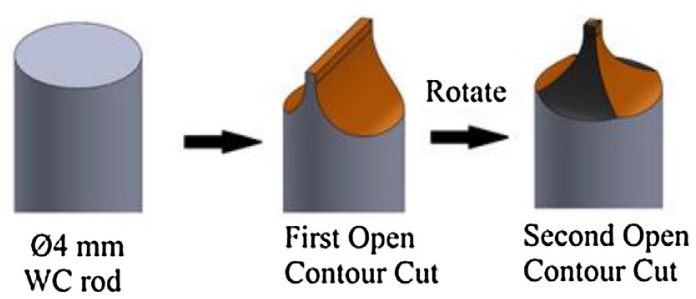

(b)

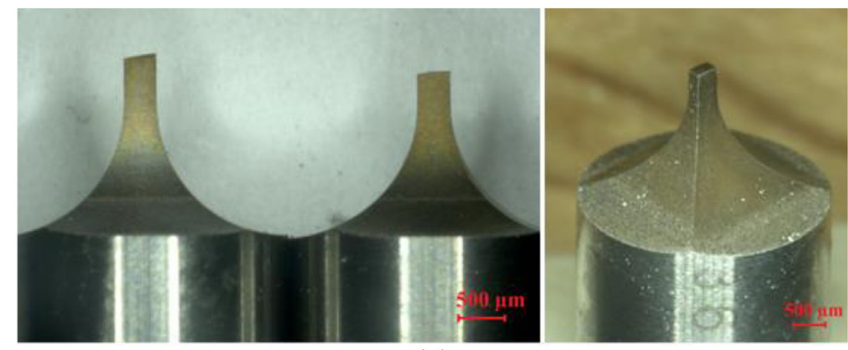

(c)

Fig. 2. (a) WEDM setup used for micro end mills fabrication, (b) Schematic representation of micro end mill fabrication process, (c) Fabricated single edge WC micro end mills.

\section{Single edge micro end mill design and its fabrication}

A novel single edge cutting tool geometry has been designed by considering the problems associated with tool runout in micro 


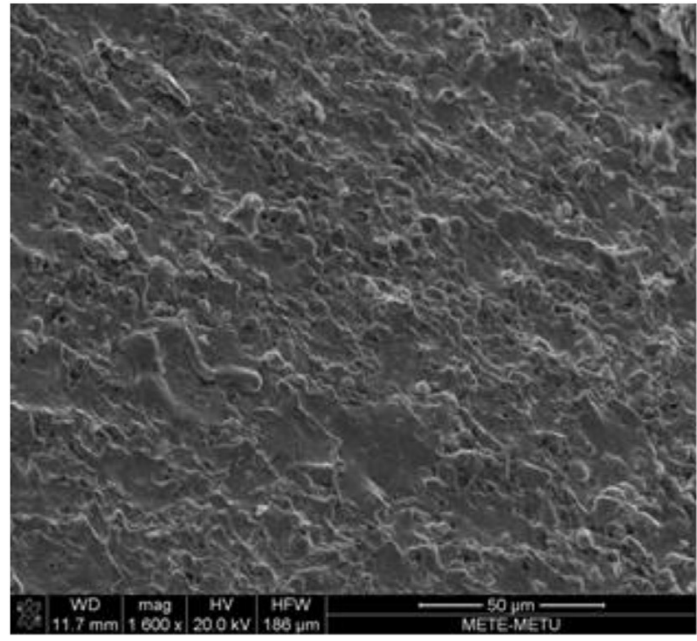

(a)

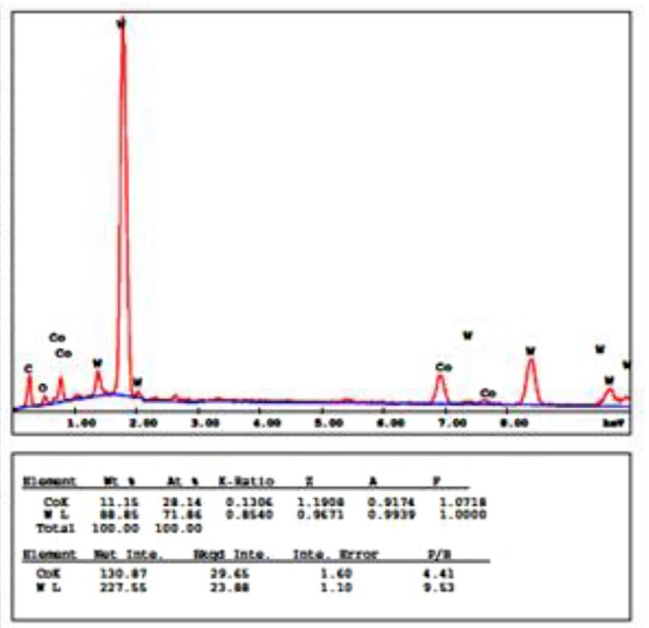

(b)

Fig. 3. (a) SEM image of a WEDMed surface, (b) EDS analysis of WEDMed surface.
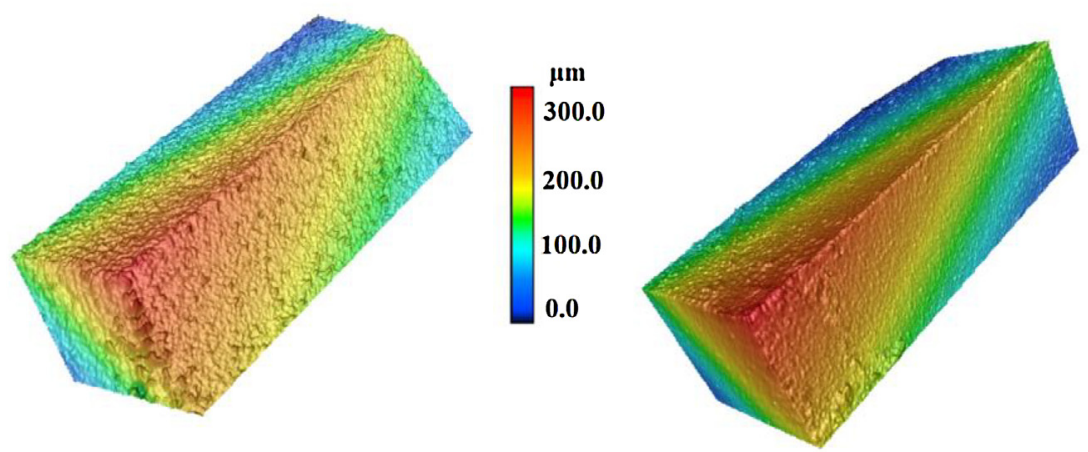

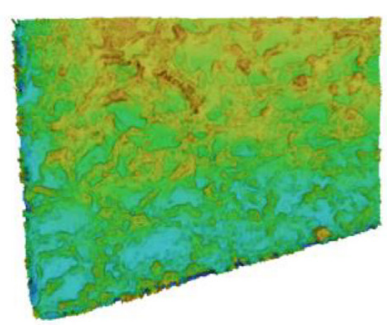

(a)

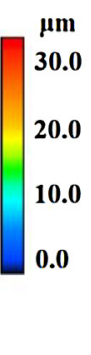

10.0
0.0

Fig. 4. 3D topography and top view of the cutting tools: (a) rough WEDMed tool, (b) finish WEDMed tool. milling. In addition, a single-edge cutting tool provides a lower tooth passing frequency, which helps conduct experiments under a stable machining process. The solid model of the proposed cutting tool geometry is depicted in Fig. 1a. Tool design parameters can be seen in Fig. 1b. The length of cutting edge, bottom and side clearance angles, neck taper angle and transition radius are considered as micro end mill design parameters. The cutting tool has a straight cutting edge, where elimination of helical flutes can further strengthen the micro end mill. The low depth of cut values used in micro milling further justify having straight cutting edges in the designed tools.

WEDM process is used to fabricate micro end mills using Sodick AP250L high precision WEDM machine with a brass wire of $0.1 \mathrm{~mm}$ diameter and oil as dielectric fluid. Ultra-fine grain tungsten carbide rods (grain size $<0.7 \mu \mathrm{m}$ ) of $4 \mathrm{~mm}$ diameter are used for micro end mill fabrication. Tungsten carbide rods are mounted on the indexer of the WEDM machine as shown in Fig. 2a with a runout of less than $1 \mu \mathrm{m}$. The tools are fabricated in two steps. Firstly, open contour machining was performed with bottom clearance angle included, then the tool is rotated based on the designed side clearance angle, and another open contour machining was performed. Depending on the required surface finish, multi-pass WEDM was performed with different rough, semi-finish, and finish WEDM passes. A careful selection of WEDM parameters made it possible to have a full control on the surface roughness, dimensional accuracy and edge radius of the fabricated micro end mills. Fig. 2 b schematically illustrates the process of micro end mill fabrication steps. Fig. 2c shows the fabricated micro end mills with a length of cut of $800 \mu \mathrm{m}$, transition radius of $1.8 \mathrm{~mm}$, neck taper angle of $90^{\circ}$ and bottom and side clearance angle of $7^{\circ}$. 


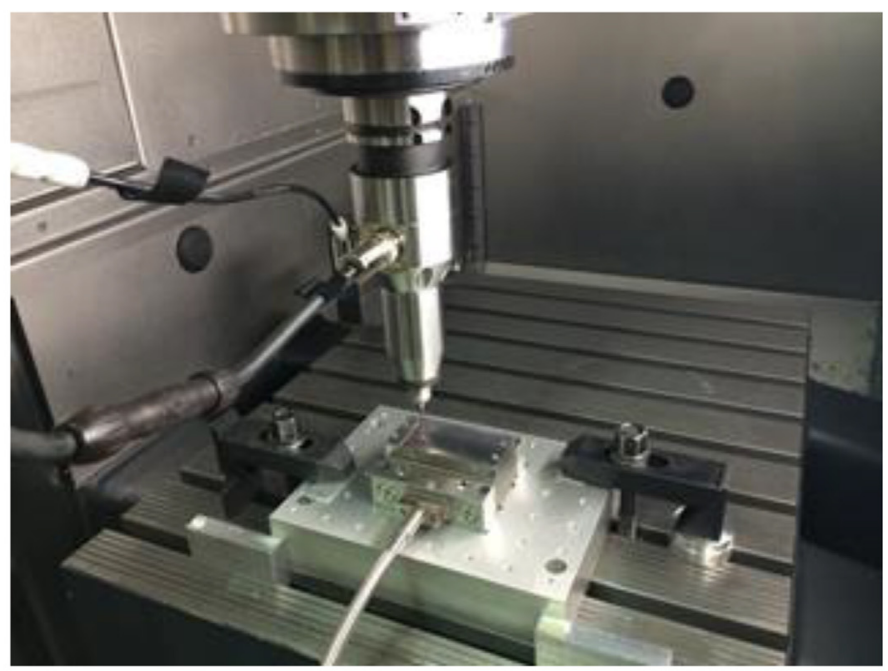

(a)
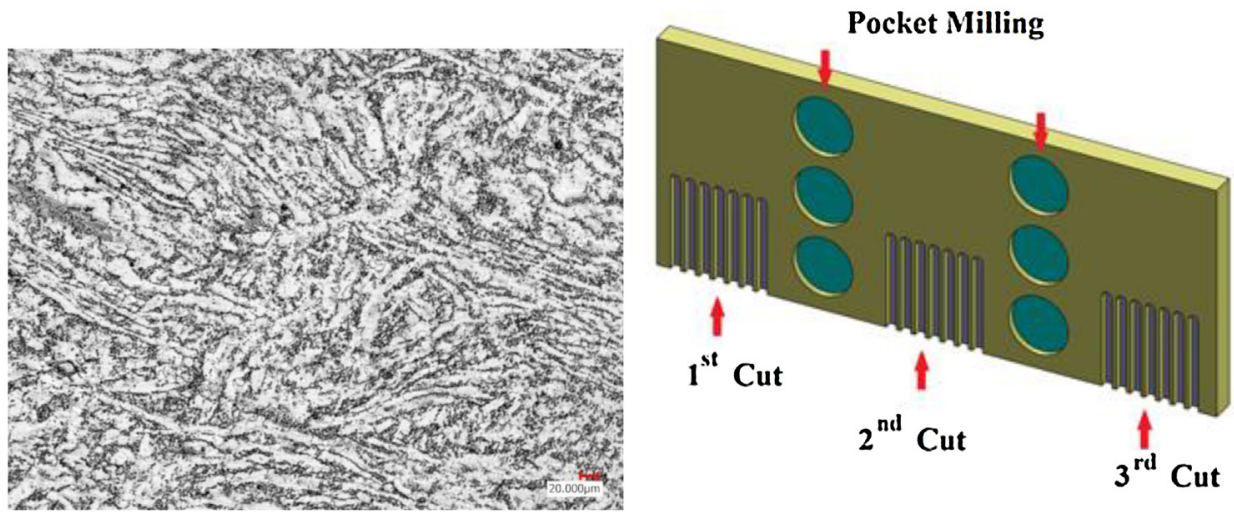

(b)

Fig. 5. (a) Experimental setup, (b) Microstructure of the titanium workpiece used in this study, (c) Schematic representation of micromilling experiments.

EDM surface is obtained as a result of craters induced by a series of successive random sparks on the workpiece. The size and depth of each individual crater together with the overlap between different craters determine the final morphology of the EDMed surface. Using high spark energies result in large and deep craters, and consequently a rough surface is obtained. Sparks with lower energies result in small craters and as a result a better surface finish can be achieved. Fig. 3(a) illustrates the SEM image of the surface obtained after WEDM process. Energy-dispersive X-ray spectroscopy (EDS) analysis of the surface is shown in Fig. 3(b). The composition of the surface is measured to be the same as bulk tungsten carbide material.

The surface roughness is known to have a significant influence on the performance of micro end mills and micromachining process outputs. In order to analyze the effect of surface roughness obtained during WEDM process on the machining performance of the micro end mills, tools with different surface roughness were fabricated. After a design of experiments approach on WEDM process parameters, the best surface roughness value was obtained as $0.15 \mu \mathrm{m}$. By applying a different set of process parameters, a surface rough- ness value of $0.6 \mu \mathrm{m}$ was also obtained. These micro tools were fabricated with two different clearance angles at $7^{\circ}$ and $14^{\circ}$. Different clearance angle and surface roughness values result in different cutting edge radii on the fabricated micro end mill. Another purpose of varying clearance angle is to change the cutting mechanics (strains, stresses, and temperatures) at the tool-workpiece interface as mentioned in the previous section. Fig. 4 illustrates 3D topography and top view of micro end mills where the difference in surface roughness and edge quality of micro end mills are visible. Table 1 summarizes the specifications of fabricated micro end mills.

\section{Preliminary micro milling experiments and observations}

In order to analyze the effect of tool conditions (surface quality, clearance angle and edge radius) on the performance of micro end mills, a series of full immersion micro milling experiments (slot micro milling) was conducted on Ti6Al4V work material using a DMG HSC 55 milling machine equipped with a high speed spindle NSK HES 510 (Fig. 5a). The work material has a lamellar microstruc- 
Table 1

Specifications of the fabricated tailored single edge micro end mills.

\begin{tabular}{|c|c|c|c|c|c|c|}
\hline Tool & $\begin{array}{l}\text { Clearance Angle } \\
\left({ }^{\circ}\right)\end{array}$ & $\begin{array}{l}\text { Surface Roughness } \\
\text { Sa }(\mu \mathrm{m})\end{array}$ & $\begin{array}{l}\text { Edge Radius } \\
(\mu \mathrm{m})\end{array}$ & $\begin{array}{l}\text { Tool Diameter } \\
(\mu \mathrm{m})\end{array}$ & $\begin{array}{l}\text { Length of cut } \\
(\mu \mathrm{m})\end{array}$ & $\begin{array}{l}\text { Neck angle } \\
\left({ }^{\circ}\right)\end{array}$ \\
\hline 1 & 7 & 0.15 & $2-3$ & 390 & 200 & 90 \\
\hline 2 & 7 & 0.6 & $4-5$ & & & \\
\hline 3 & 14 & 0.15 & $1.5-2.5$ & & & \\
\hline 4 & 14 & 0.6 & 4-5 & & & \\
\hline
\end{tabular}
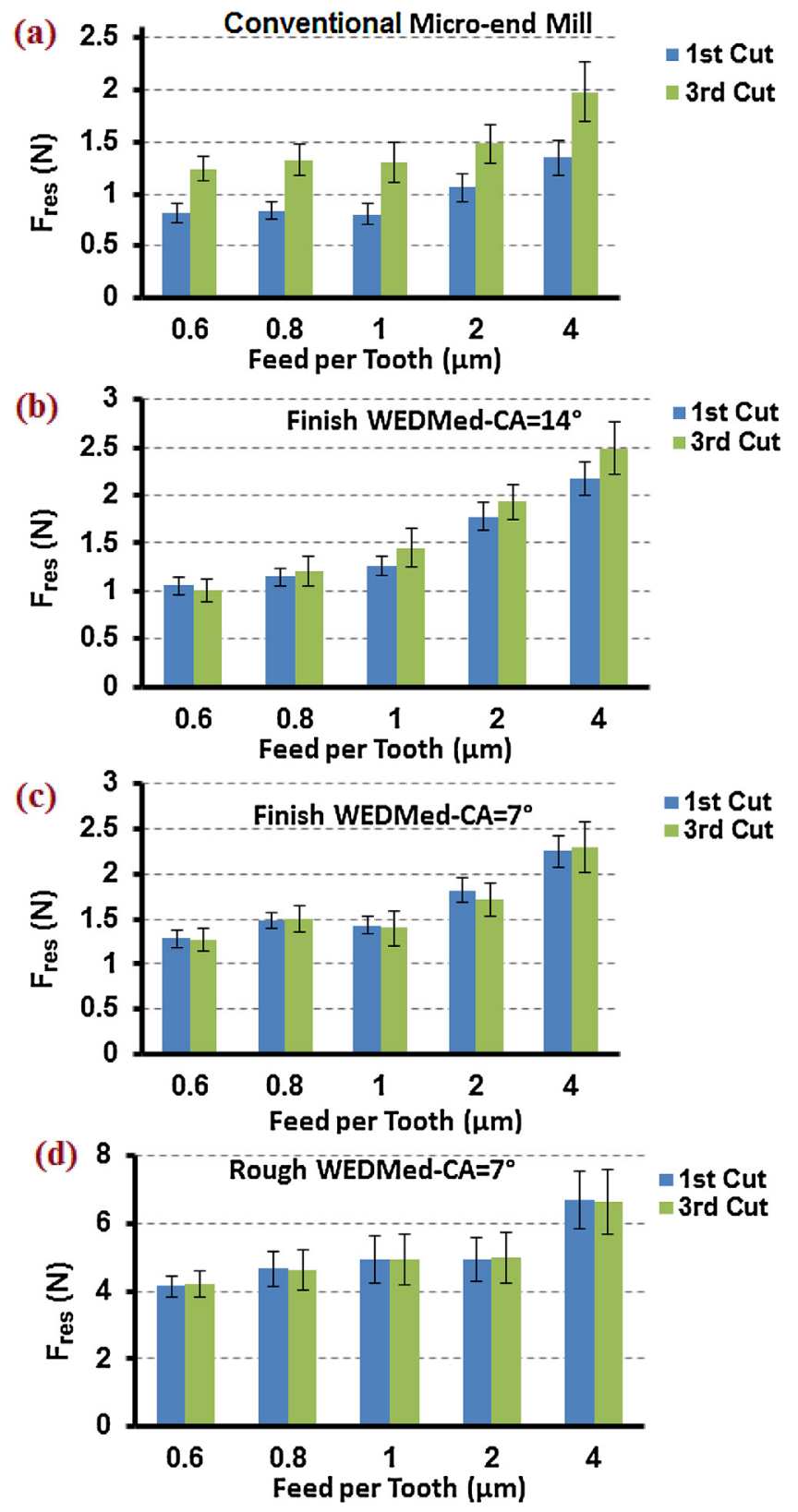

Fig. 6. RMS of the resultant force: (a) Conventional micro end mill, (b) Finish WEDMed-CA $=14^{\circ}$, (c) Finish WEDMed-CA $=7^{\circ}$, (d) Rough WEDMed-CA $=7^{\circ}$.

ture that has been shown to be favorable for micro milling in the literature [26] (Fig. 5b). The experiments were performed at feed per tooth values of $0.6,0.8,1,2$, and $4 \mu \mathrm{m} /$ tooth, while spindle speed and depth of cut were kept constant at 28,000 rpm and $30 \mu \mathrm{m}$, respectively. The depth of cut is between 5 and $10 \%$ of the tool diameter as used in practice. No coolant was used during the experiments. Fig. 5a shows the experimental setup for micro milling tests. For comparison purposes, a commercial micro end mill with helical geometry and $0.4 \mathrm{~mm}$ diameter was also used in the experiments. The up-sharp tool has a cutting edge radius of $2 \mu \mathrm{m}$. Machining forces were measured using Kistler mini force dynamometer (9256C1, max $250 \mathrm{~N}$ ).

During micro milling experiments, a methodology was followed which allows for long term testing of micro end mills. Experiments start with slot milling operation at different feed values and following completion of the slot milling tests, tools were used in circular pocket milling operation as summarized in Table 2. After completing the circular pocket operations, tools were used in slot milling 

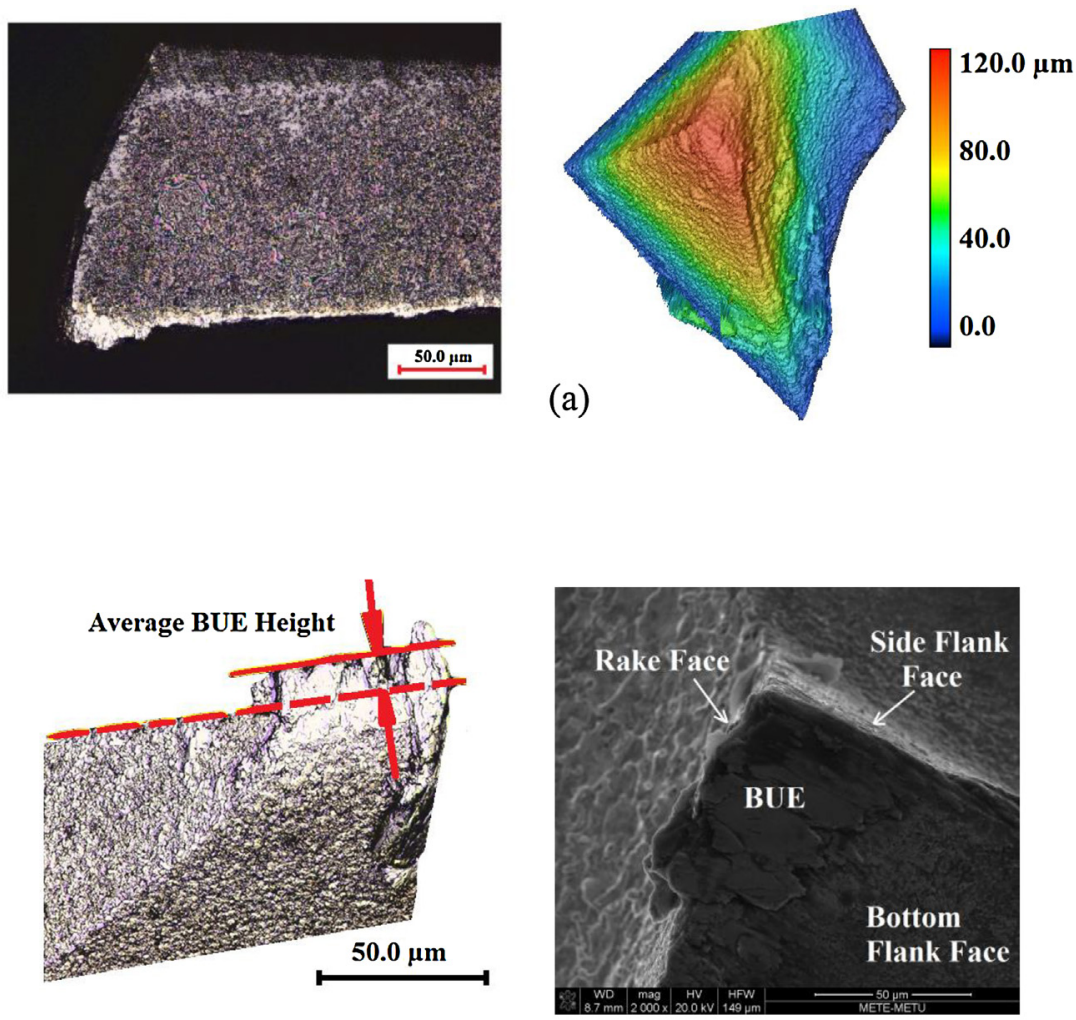

(b)

(c)

Fig. 7. (a) Edge condition after micromilling, (b) Measurement of average BUE height by 3D laser scanning microscope, (c) SEM image of the BUE formed in a finish WEDMed-CA $=7^{\circ}$.

Table 2

Experimental Conditions.

\begin{tabular}{llll}
\hline Cutting Tools & Cutting Speed & Axial Depth of Cut & Feed rate (um/tooth) \\
\hline Conventional Micro End Mill, Tools 1, 2, 3,4 & 28,000 & 30 & $0.6,0.8,1,2,4$ \\
\hline
\end{tabular}

operation as before and machining forces were measured again. The purpose of circular milling operation is to extend the machining time so that issues like tool wear and built-up edge formation can be observed. Fig. 5b explains the experimental methodology followed in this study.

Fig. 6 shows the root mean square (RMS) of the resultant force for each milling case. The resultant force is calculated as $\sqrt{F_{x}^{2}+F_{y}^{2}+F_{z}^{2}}$. Micro end mill fabricated to have large surface roughness and clearance angle of $14^{\circ}$ was observed to break at the beginning of the test, so no results are reported for that tool. This premature breakage may be attributed to the weakening effect of both large clearance angle and larger craters due to higher spark energies applied in tool fabrication. As expected, the RMS value of the resultant force increase between first and third experiments. The magnitude of resultant forces for conventional end mill and fabricated end mills having low surface roughness with $7^{\circ}$ and $14^{\circ}$ clearance angles are close to each other. While there is a significant increase in resultant forces between first and third slot milling operations for the conventional micro end mill, the amount of force increase in fabricated micro end mills are smaller. Fabricated micro end mill with $7^{\circ}$ clearance angle seems to be the most favorable considering largest feed value of $4 \mu \mathrm{m} /$ tooth. Larger forces are directly related to cutting edge radius as seen in Fig. $6 \mathrm{~d}$.

Investigation of the cutting edges after micro milling experiments shows edge rounding and built-up edge (BUE) formation.
Fig. 7a shows the optical and 3D laser scanning microscope image of the cutting edge of the conventional tool after micro milling tests. The edge radius of the micro end mill has been increased to $6 \mu \mathrm{m}$ from an initial radius of $2 \mu \mathrm{m}$ and a built-up edge formation took place. Fig. $7 \mathrm{~b}$ shows the BUE formation on the cutting edge with a fabricated tool of low surface roughness and $7^{\circ}$ clearance angle. Having a straight cutting edge leads to a larger stable BUE formation in front of the tool compared to a conventional tool which serves the purpose of this study where the influence of BUE on micro milling is investigated. The micro end mill with $7^{\circ}$ clearance angle is used in the remainder of the study.

\section{Investigation of micro milling process outputs in the presence of BUE}

This section aims to further investigate the effect of BUE on micro milling process outputs such as micro milling forces, surface quality, dimensional accuracy and burr formation. The same experimental setup used in the previous section was also used. Single edge micro end mills with a nominal diameter of $0.4 \mathrm{~mm}$ diameter with $200 \mu \mathrm{m}$ length of cut were used in the experiments. Slot micromilling experiments were performed under the conditions summarized in Table 3, while feed rate is kept constant at $4 \mu \mathrm{m} /$ tooth. 


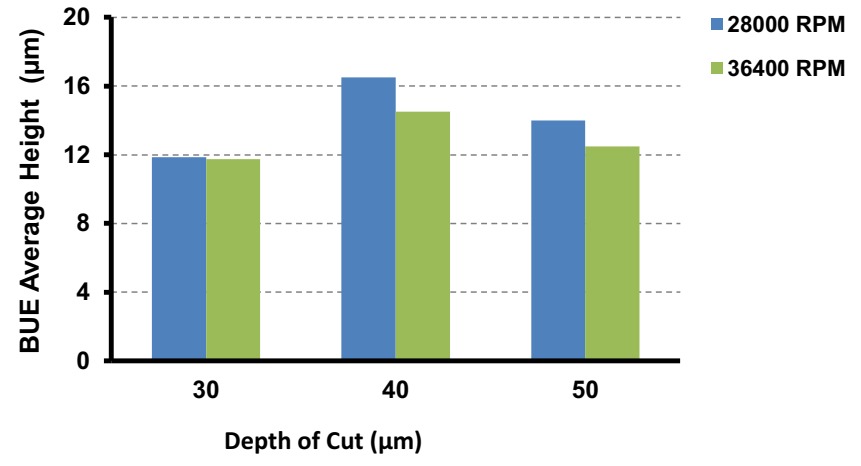

(a)

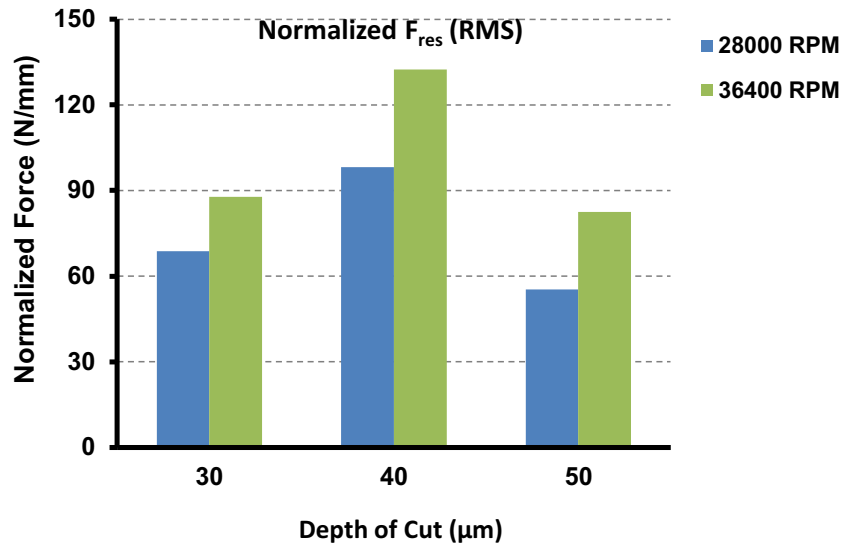

(b)

Fig. 8. (a) Average BUE height, (b) Normalized resultant force.

Table 3

Experimental conditions used for BUE studies.

\begin{tabular}{lll}
\hline Exp \# & Spindle Speed $(\mathrm{rpm})$ & Depth of cut $(\mu \mathrm{m})$ \\
\hline 1 & 28,000 & 30 \\
2 & & 40 \\
3 & & 50 \\
4 & 36,400 & 30 \\
5 & & 40 \\
6 & & 50 \\
\hline
\end{tabular}

The feed selection corresponds to rough micro machining cases where maximizing material removal rate is the goal. The protective effect of BUE in this case would be the most useful. For each experiment the average BUE height (as defined in Fig. 7b), micro milling forces, surface roughness, and burr parameters were measured. The average BUE length is measured by laser scanning microscope (Keyence VX-110) as shown in Fig. 8a. BUE height increases with increasing depth of cut from $30 \mu \mathrm{m}$ to $40 \mu \mathrm{m}$, but decreases with increasing depth of cut from $40 \mu \mathrm{m}$ to $50 \mu \mathrm{m}$. It must be noted that the measurements are quite close to each other by considering the geometry of BUE in Fig. 7b. The influence of increasing speed on average BUE height is also not significant. However, the influence of cutting speed and depth of cut on the resultant forces are significant. In order to remove the effect of depth of cut variations due to BUE formation, RMS of the resultant forces are normalized with respect to depth of cut measurements after the experiments using 3D laser scanning microscope. There seems to be a correlation between BUE height and resultant forces, but it must be noted that cutting forces also reflect the material response. The titanium alloy
Ti6Al4V used in the experiments has a laminar micro structure with 10 and $20 \mu \mathrm{m}$ grain size.

Fig. 9 shows the areal surface roughness (arithmetic mean height, Sa) measurements corresponding to each experimental case. 3D laser topography of the microchannels are shown in Fig. 9a for experiments 4,5 and 6 . Analysis of the surface roughness of the experiments revealed that a better surface roughness has been achieved corresponding to the largest BUE height which also corresponds to largest machining forces. This can be mainly because of the burnishing effect of the BUE on the surface. Similar results were also observed in Oliaei and Karpat [19] in micro turning experiments. Our experimental results are comparable to surface roughness values reported in Wang et al. [12] where the focus was finish micro milling experiments. It means that comparable results can be obtained in terms of surface roughness with the tailored tools. As the BUE size gets larger, it is likely that some loose bits will be smeared to the bottom surface of the microchannel which is expected to hinder the surface quality.

The final issue considered is the burr formation. Fig. 10a illustrates SEM images of the burrs formed under experimental conditions of Table 3. SEM is used to measure burr width and a laser microscope is used to measure burr height. The measured burr height and width for each cutting tool are shown in Fig. 10b. Depth of cut is the most influential factor in burr formation. The burr height and width increase with increasing depth of cut.

It is important to note that BUE formation at the cutting edge affects the width and depth of the microchannel. When conventional micro end mills are used, which comes in standardized diameters, BUE formation hinders dimensional control during machining. However, when tailored tools are used, tool diameter 


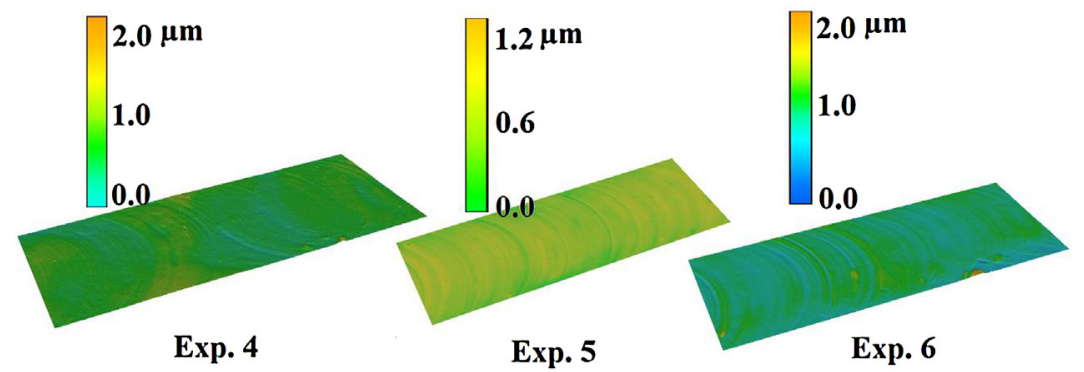

(a)

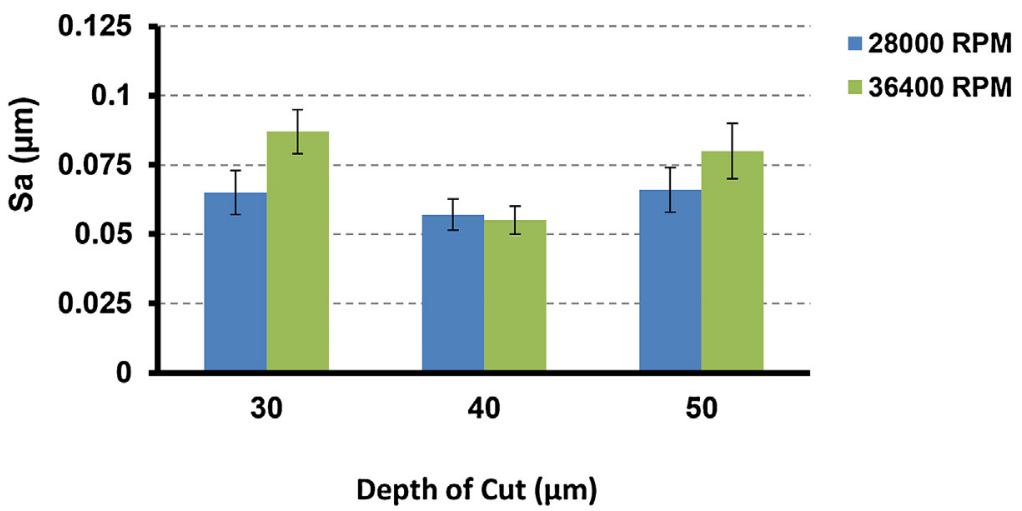

(b)

Fig. 9. (a) 3D surface topography of the machined microchannels, (b) Arithmetic mean height (Sa).

Table 4

Measured depth and width of microchannels.

\begin{tabular}{|c|c|c|c|}
\hline Experiment \# & Desired Microchannel Depth $(\mu \mathrm{m})$ & Measured Microchannel Depth $(\mu \mathrm{m})$ & Measured MicrochannelWidth $(\mu \mathrm{m}$ \\
\hline 1 & 30 & 31 & 394 \\
\hline 2 & 40 & 39 & 392 \\
\hline 3 & 50 & 52 & 389 \\
\hline 4 & 30 & 33 & 383 \\
\hline 5 & 40 & 42 & 386 \\
\hline 6 & 50 & 48 & 391 \\
\hline
\end{tabular}

can be adjusted based on the BUE formation to control dimensional tolerances. Therefore, it is important to have predictive ability on BUE size as a function of process parameters. Table 4 shows the measured microchannel width and depth values for each experiment (Fig. 11).

\section{Investigating the protective effect of BUE during micro milling}

In order to analyze the protective effect of built-up edge formation on tool life of the fabricated micro end mills, long term micro milling experiments have been done. For this purpose 80 microchannels with a length of $50 \mathrm{~mm}$ have been machined at a spindle speed of $28000 \mathrm{rpm}$, feed rate of $4 \mu \mathrm{m} /$ tooth and a depth of cut of $50 \mu \mathrm{m}$. It corresponds to Exp \#3 in Table 3. The machining process has been interrupted after machining each 20 microchannels, and tool condition is monitored using 3D laser scanning microscope. Fig. 12 illustrates the SEM image of the BUE formed at the 80th microchannel.

For each microchannel cutting forces are also recorded. Fig. 13(a-d) illustrates the measured cutting forces for the first, second, 40th and 80th microchannel, respectively. Between the first and second microchannels, there is a significant increase in $\mathrm{y}$ - direction forces while the forces in $\mathrm{x}$ and $\mathrm{z}$ directions are stable. This increase is believed to be related to edge rounding of the cutting edge, which affects the mechanics of the cutting process. Increasing the edge radius created suitable conditions of material accumulation in front of the tool. With the stable BUE formation in place, the cutting forces almost remain at the same value through 80th microchannels.

At the end of long term experiments, to gain an understanding about the possibility of chemical reaction between tool and work, BUE has been removed from the cutting tool using a cleaning process. An EDS analysis was performed in a location exactly underneath the removed BUE. The EDS analysis results are shown in Fig. 14. EDS analysis of the bulk tool material is shown in Fig. 14(a). The cobalt content of the tool material underneath BUE has been decreased from $11.6 \mathrm{wt} \backslash \%$ to about $8 \mathrm{wt} \backslash \%$ and the tungsten content has been decreased from $88 \%$ to $86 \%$. This decrease has been explained by Hartung and Kramer [27] as the formation of TiC layer at the tool chip interface which was replenished by the carbon atoms removed from the WC grains on the tool. The results 


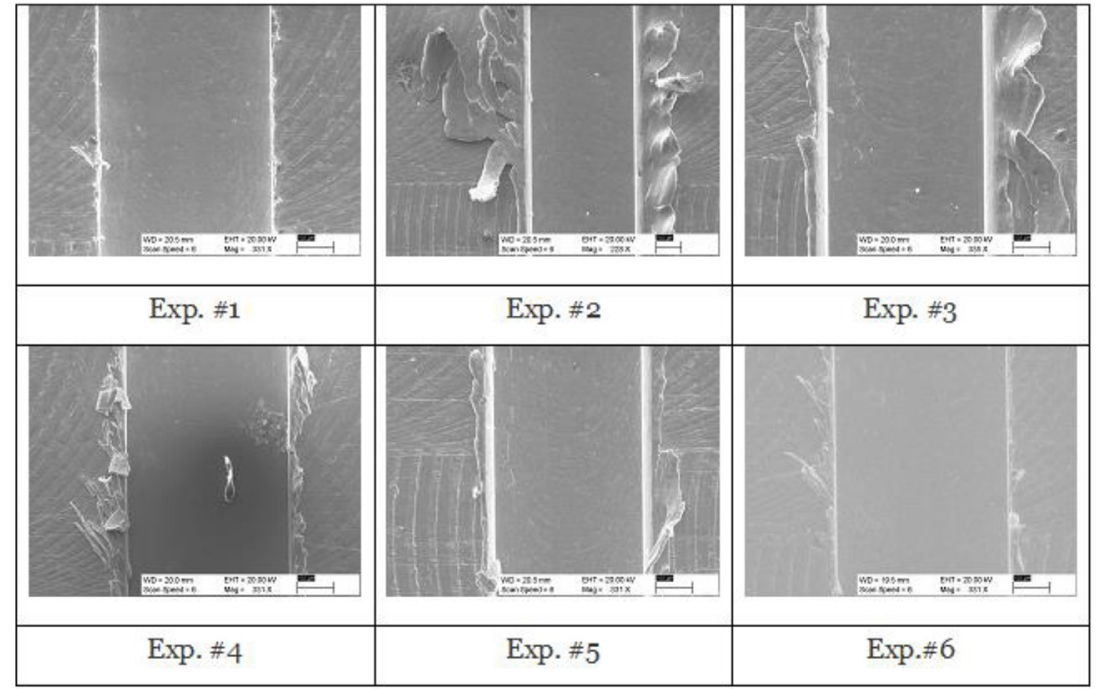

(a)

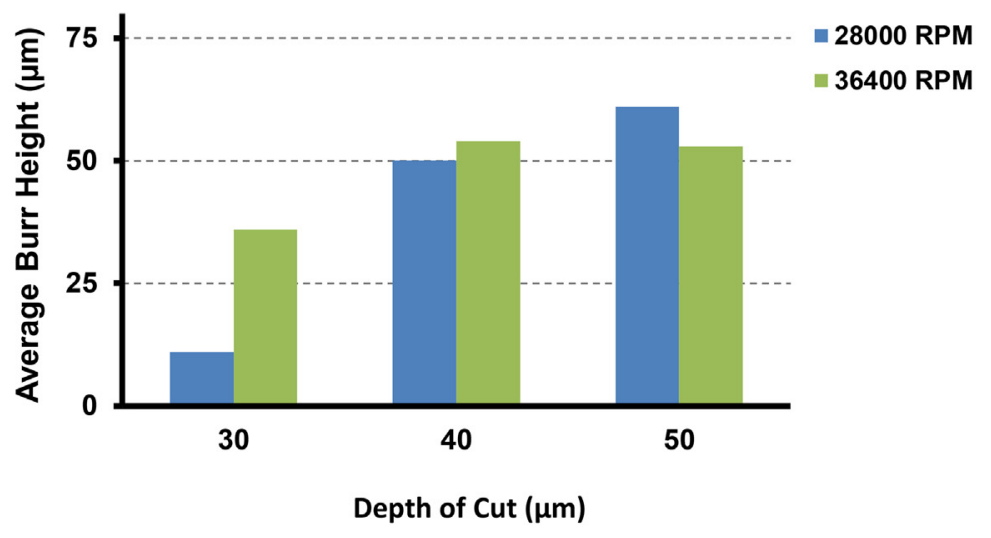

(b)

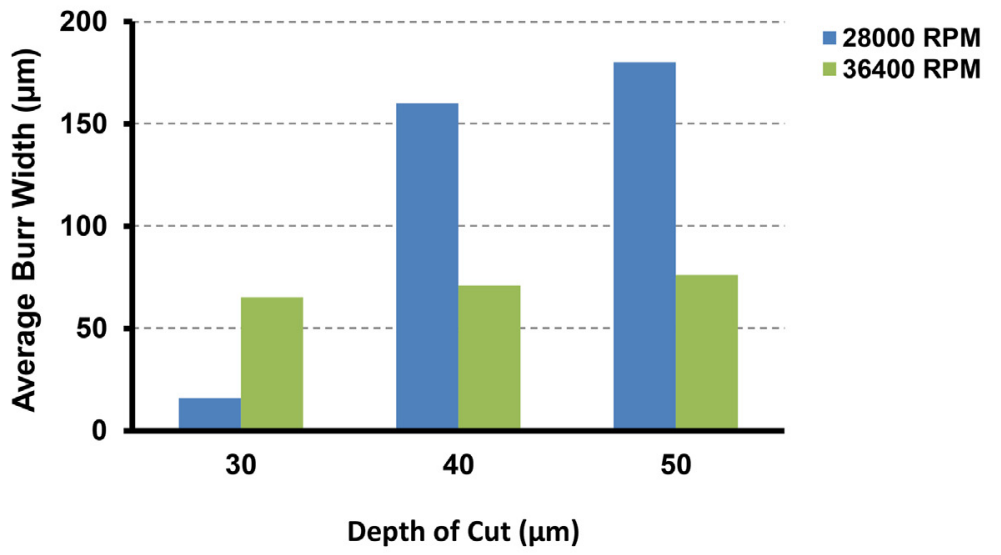

(c)

Fig. 10. (a) SEM image of the burrs formed under experimental conditions of Table 2, (b) Average burr height, (c) Average burr width. 


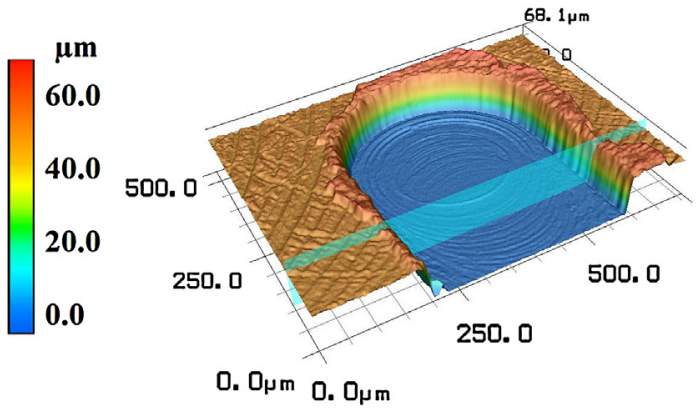

(a)

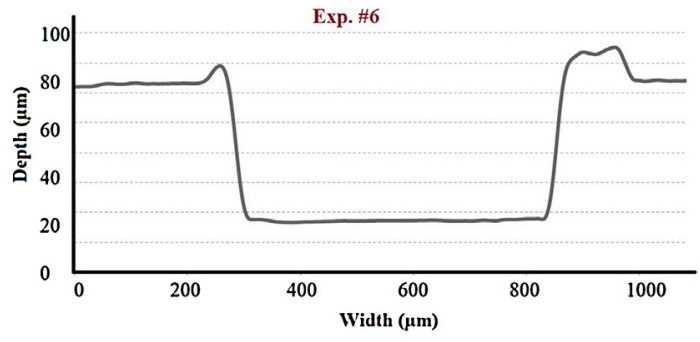

(b)

Fig. 11. Microchannel of Exp. \#6. (a) 3D image, (b) Microchannel Profile. A height magnification of $200 \%$ is used.

obtained in this section are in agreements with the results of Oliaei and Karpat [19]. A stable BUE was shown to protect the cutting edge in micro turning process. The same protective effect is also obtained in micro milling process using tailored micro end mills.

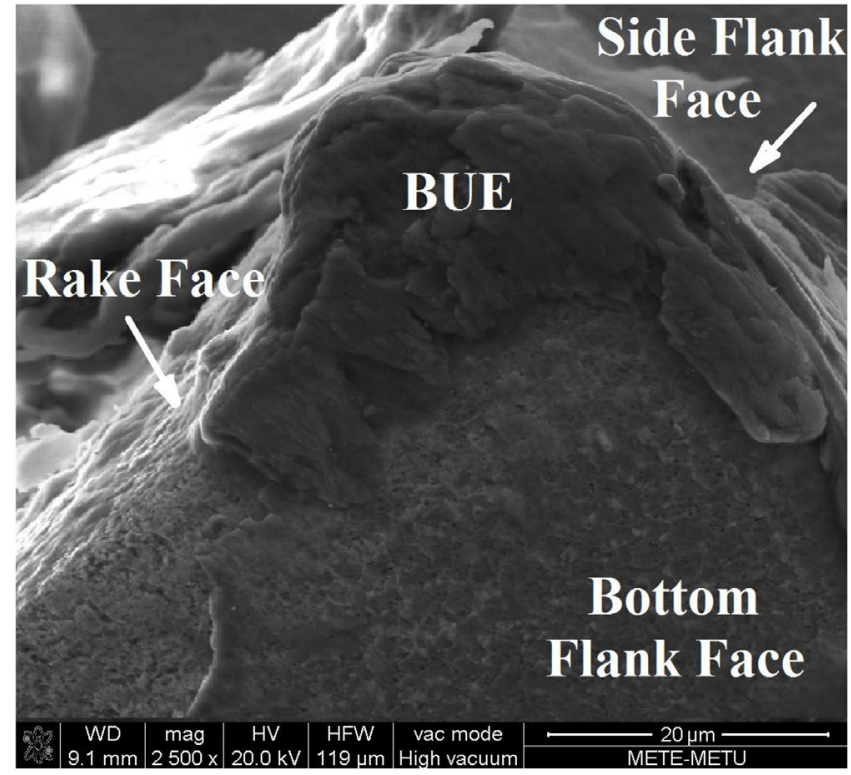

Fig. 12. SEM image of BUE after machining 80 microchannels.

\section{Conclusions}

The influence of BUE on the process outputs in micro milling has been studied using a tailored single edge micro end mill. The results can be summarized as follows:

- The surface roughness of the micro end mill fabricated with wire EDM is an important factor on the success of the process.

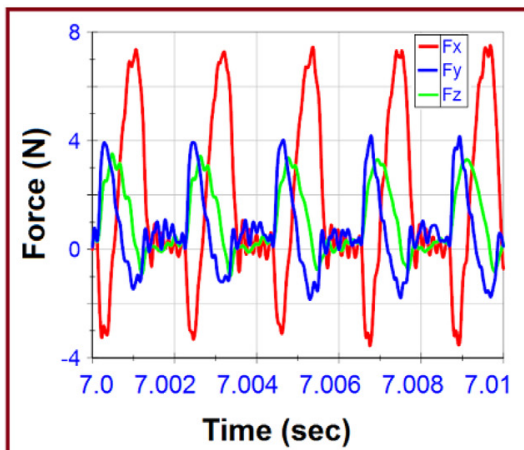

(a)

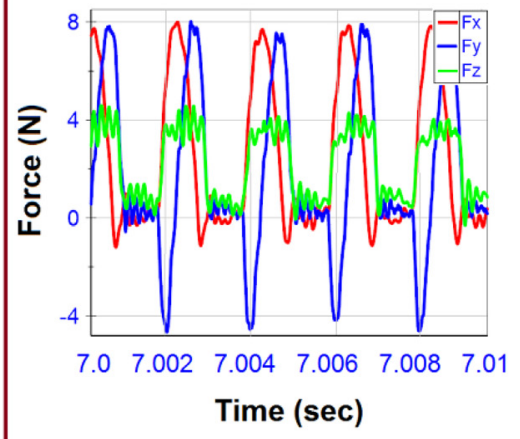

(c)

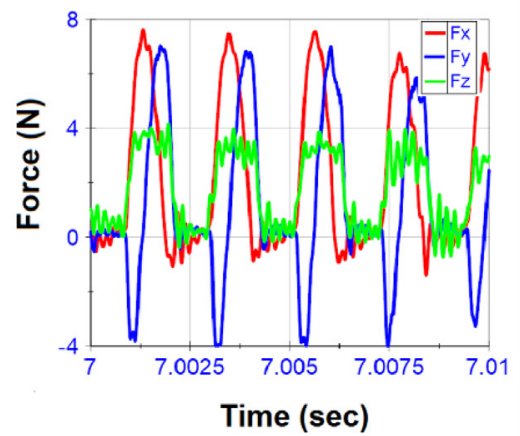

(b)

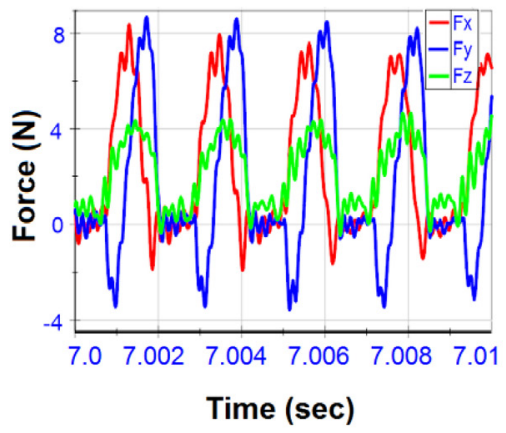

(d)

Fig. 13. Measured cutting forces for: (a) First microchannel, (b) Second microchannel, (c) 40th microchannel, (d) 80th microchannel. 


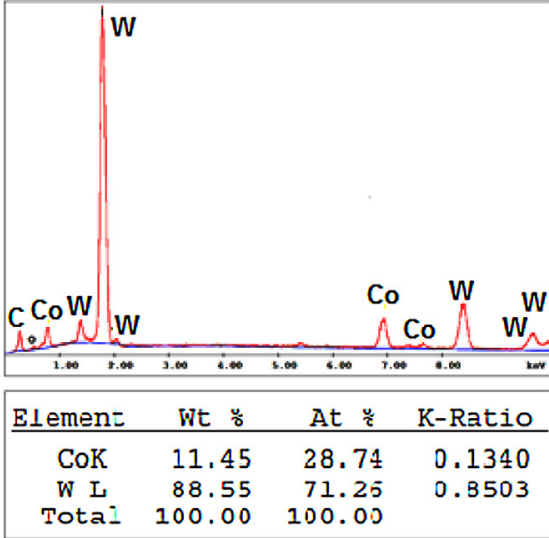

(a)

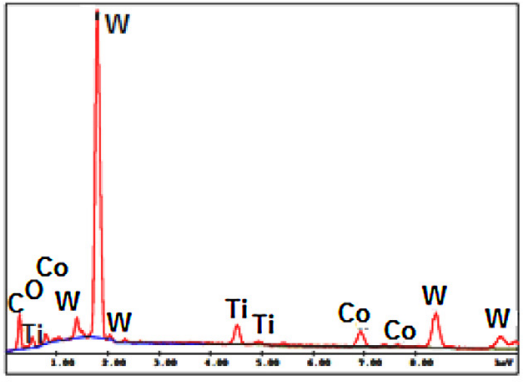

\begin{tabular}{crrr|}
\hline Element & Wt \& & \multicolumn{1}{c}{ At 8} & K-Ratio \\
\hline TiK & 5.61 & 16.24 & 0.0498 \\
CoK & 7.88 & 18.53 & 0.0915 \\
W L & 86.51 & 65.23 & 0.8256 \\
Total & 100.00 & 100.00 & \\
\hline
\end{tabular}

(b)

Fig. 14. EDS analysis of (a) bulk tool material, (b) Underneath of the BUE.

- A micro end mill with low clearance angle yielded the most stable condition in BUE formation. The performance of the tailored micro end mill is observed to be acceptable.

- It has been observed that, larger BUE sizes resulted in larger resultant forces. Surface roughness improved with increased BUE size. It must be noted that a large unstable BUE would deteriorate the surface finish. The selection of feed and depth of cut for a given work material is an important consideration.

- Increasing cutting speed did not improve surface roughness under the experimental conditions considered in this study.

- There is no correlation between BUE and burr parameters. Large forces yielded larger burrs.

- Obtaining a stable BUE during machining helps increase the tool life, which is an important issue in roughing operations especially in micro mold making.

- The ability to predict and control BUE size, together with tailored tool design, may be beneficial in micro milling practice.

\section{Acknowledgements}

The authors would like to thank The Scientific and Technological Research Council of Turkey (TÜBITAK-110M660, National Young Researcher Career Development Program) and State Planning Organization of Turkey (HAMIT-Micro System Design and Manufacturing Research Center).

\section{References}

[1] Dornfeld D, Min S, Takeuchi Y. Recent advances in mechanical micromachining. CIRP Ann Manuf Technol 2006;55(2):745-68.

[2] Paulo Davim J, Jackson Mark J, editors. Nano and Micromachining. Wiley Online Library; 1807., http://dx.doi.org/10.1002/9780470611807. ISBN 9781848211032.

[3] Denkena B, Biermann D. Cutting edge geometries. CIRP Ann Manuf Technol 2014;63(2):631-53.

[4] Machining of Titanium Alloys, ISBN: 978-3-662-43901-2 (Print) 978-3-662-43902-9 (Online), In: Paulo Davim J, editor.

[5] Veiga C, Davim JP, Loureiro AJR. Review on machinability of titanium alloys: the Process perspective. Rev Adv Mater Sci 2013;34:148-64.

[6] Lauro CH, Sérgio Filho SLMR, Brandão LC, Davim JP. Analysis of behaviour biocompatible titanium alloy (Ti-6Al-7Nb) in the micro-cutting. Measurement 2016;93:529-40.

[7] Bandyopadhyay BP. Mechanism of formation of built-up edge. Precision Eng 1984;6(3):148-51.

[8] Childs THC. 2011: Towards simulating built-up-edge formation in the machining of steel. CIRP J Manuf Sci Technol 2011:4:57-70.

[9] Ikuta A, Shinozaki K, Masuda H, Yamane Y, Kuroki H, Fukaya Y. Consideration of the adhesion mechanism of Ti alloys using a cemented carbide tool during the cutting process. J Mater Process Technol 2002;127(2):251-5.

[10] Thepsonthi T, Özel T. 3-D finite element process simulation of micro-end milling Ti-6Al-4ÖV titanium alloy: experimental validations on chip flow and tool wear. J Mater Process Technol 2015;221:128-45.
[11] Kovvuri V, Wang Z, Araujo A, Bukkapatnam STS, Hung WNP. Built-up edge formation in micromilling. In: Proceedings of the ASME 2015 Internationa Mechanical Engineering Congress and Exposition IMECE2015 November 13-19, 2015. 2017.

[12] Wang Z, Kovvuri V, Araujo A, Bacci M, Hung WNP, Bukkapatnam STS. Built-up-edge effects on surface deterioration in micro milling processes. J Manuf Process 2016, http://dx.doi.org/10.1016/j.jmapro.2016.03.016.

[13] Ucun I, Aslantas K, Bedir F. The performance of DLC-coated and uncoated ultra-fine carbide tools in micromilling of Inconel 718. Precision Eng 2015;41:135-44.

[14] Aslantas K, Hopa HE, Percin M, Ucun I, Cicek A. Cutting performance of nano-crystalline diamond (NCD) coating in micro-milling of Ti6Al4V alloy. Precision Eng 2016;45:55-66.

[15] Iwata K, Ueda K. Fundamental analysis of the mechanism of built-up edge formation based on direct scanning electron microscope observation. Wear 1980;60(52):329-37.

[16] Mills B, Hao CS, Qi HS. Formation of an adherent layer on a cutting tool studied by micro-machining and finite element analysis. Wear 1997;208:61-6.

[17] Kümmel J, Gibmeier J, Müller E, Schneider R, Schulze V, Wanner A. Detailed analysis of microstructure of intentionally formed built-up edges for improving wear behaviour in dry metal cutting process of steel. Wear 2014;311:21-30.

[18] Kümmel J, Braun D, Gibmeier J, Schneider J, Greiner C, Schulze V, et al. Study on micro texturing of uncoated cemented carbide cutting tools for wear improvement and built-up edge stabilisation. J Mater Process Technol 2015;215:62-70.

[19] Oliaei SNB, Karpat Y. Investigating the influence of built-up edge on forces and surface roughness in micro scale orthogonal machining of titanium alloyTi6Al4V. J Mater Process Technol 2016;235:28-40.

[20] Vasile MJ, Friedrich CR, Kikkeri B, McElhannon R. Micrometerscale machining: tool fabrication and initial results. Precision Eng 1996;19(2):180-6.

[21] Fleischer J, Deuchert M, Ruhs C, Kuhlewein C, Halvadjiysky G, Schmidt C. Design and manufacturing of micro milling tools. Microsyst Technol 2008;14(9-11):1771-5.

[22] Morgan CJ, Vallance RR, Marsh ER. Micro machining glass with polycrystalline diamond tools shaped by micro electro discharge machining. J Micromech Microeng 2004;14(12):1687.

[23] Asad A, Masaki T, Rahman M, Lim H, Wong Y. Tool-based micromachining. J Mater Process Technol 2007:192:204-11.

[24] Zhang Z, Peng H, Yan J. Micro-cutting characteristics of EDM fabricated high-precision polycrystalline diamond tools. Int J Mach Tools Manuf 2013;65:99-106.

[25] Cheng X, Nakamoto K, Sugai M, Matsumoto S, Wang Z, Yamazaki K. Development of ultra-precision machining system with unique wire edm tool fabrication system for micro/nano-machining. CIRP Ann Manuf Technol 2008:57(1):415-20.

[26] Attanasio A, Marcello GM, Pola A, Ceretti E, Giardini C. Influence of material microstructures in micromilling of Ti6Al4 V Alloy. Materials 2013;6:4268-83, http://dx.doi.org/10.3390/ma6094268.

[27] Hartung PD, Kramer BM. Tool wear in Titanium machining. Ann CIRP $1982 ; 32: 75-80$. 